Doi: HTTPS://DOI.ORG/10.23910/2/2020.0382

\title{
Conventional Genetic Improvement Methods in Medicinal and Aromatic Plants: A Review
}

\author{
Ravi Bhardwaj;, Kamal Sharma, Dushyant Kumar Sharma and Prem Prakash
}

College of Horticulture and Forestry Neri, Hamirpur, Dr. Y. S. Parmar University of Horticulture and Forestry, Nauni, Solan, H.P. (177 001), India

\author{
Corresponding Author \\ Ravi Bhardwaj \\ e-mail: bhardwajravi86@gmail.com
}

\author{
Article History \\ Article ID: IJEP0382 \\ Received in $02^{\text {nd }}$ September, 2020 \\ Received in revised form $17^{\text {th }}$ September, 2020 \\ Accepted in final form $28^{\text {th }}$ September, 2020
}

\begin{abstract}
The collection of medicinal and aromatic plants from the wild has been declining during the last decade; therefore it is necessary to develop highly productive cultivars, combined with appropriate cultivation and intensive agricultural techniques. Majority of the improved cultivars of medicinal and aromatic plants under cultivation have been created by conventional selection methods including individual, mass or special selection methods. Furthermore, outstanding results have been reported through hybridization and mutation. Highly productive cultivars of Mentha spicata, Ocimum americanum and Salvia officinalis have been developed through selection. Improved strains of Cymbopogon flexuosus, Melissa officinalis, Solanum laciniatum and Thymus vulagaris through intraspecific crossing resulting in changes in their active agents have been developed. Mutation breeding using physical and chemical mutagens have been successfully employed in Jasminum grandiflorum and Mentha arvensis. Hybrids of Thymus vulgaris and Artemisia annua have been developed through hybridization. According to Directorate of medicinal and aromatic plants research (DMAPR), twenty five new improved varieties of medicinal plants of fourteen species and seven varieties of aromatic plants of six species have been developed under different research institutes and Agricultural Universities in the country. Thus, improved cultivars with useful characters, resistance to biotic and abiotic stress, increased yield and early maturity have been developed through different conventional genetic improvement methods. Also hybrids with increased productivity, wider adaptability, wider application and better resistance to environmental factors have been produced through hybridization.
\end{abstract}

Keywords: Hybridization, medicinal and aromatic plants, selection

\section{Introduction}

To meet the increasing demand of medicinal and aromatic plants as a raw material for herbal products, it is necessary to develop highly productive cultivars, combined with appropriate cultivation and intensive agricultural techniques. Many medicinal and aromatic plants are collected even today from wild populations. These populations are the starting genetic material used for cultivation, and therefore it is of great importance to be in possession of the entire range of variation found in nature. This variation is the basis for selection.

In harmony with recent regulations (WHO), the quality of medicinal and aromatic plants and their products have to fulfill requirements of safety, efficacy and stability. To meet these demands, more detailed knowledge on chemical or production-biological properties of species are required. However, the reliable standard production of raw, supposed to be achieved by using GAP system of cultivation, requires cultivars of high productivity. Large numbers of breeding and registration of medicinal and aromatic plant cultivars are being reported from different countries.

The goal of breeding varies in the great deal. In some cases, the improvement of the morphological and biological characters of plants has to be achieved. Modification of the accumulation level of the active agents can be chosen for the goal of the selection either the increase or decrease of the biologically active compounds are necessitated. Especially from point of view the cultivation practice the life form of the species has to be modified. In some cases, the success of cultivation depends on resistance of species. In this respect, cultivars of high pathogen resistance (Mentha piperita, Hypericum perforatum) and cold tolerance (Rosmarinus officinalis) were selected and registered.

\section{Exploitation of Natural Biodiversity}

The chemical diversity of the plant kingdom is a well-known phenomenon and has been utilized for improving medicinal and aromatic plant production since centuries. The main directions of investigations are as follows: 
2.1. Search for inter, or intraspecific distribution of welldefined active compounds is one of the most important goal of analysis, even today. As an example, the well known chamazulene and bisabolol-types of Matricaria recutita were found, checking 29 local populations in Bulgaria, two new chemotypes of the species accumulating jaceidin and chrysosplanitin were identified in Slovakia, while in contrast no special chemotypes of practical importance were found in Greece. In Argentina, the presence of thymol, thymolcarvacrol, and pulegone types of Minthostachys verticillata were detected in different regions.

2.2. The identification and selection of plants (chemotypes) with absence of compounds of adverse effects has become an important subject too. Correlation analysis between the chromosome number and production ability of the natural populations is a new line of investigation. In this respect, works concerning Marrubium vulgare, Acorus calamus and 31 other species by Murin are worth to mention.

2.3. Number of natural populations and their active agents were checked for special biological activity. Origanum species collected from Euboea and Crete were characterized according to their antimicrobial and cytotoxic activities. Ocimum species from India were evaluated analyzing their efficacy against Aspergillus niger, Rhizopus stolonifer, Escherichia coli, Bacillus subtilis and B. megaterium. The essential oil of $O$. basilicum var. purpurescens was the most potent according to the results.

\section{Conventional Genetic Improvement Methods}

These are dependent on the type of reproduction and pollination mechanisms in plants. A selection program should be based on natural and/or induced variation, examination of this variation, identification of the best plant, its vegetative propagation, and finally releasing the new clone to the farmers for commercial cultivation. In species where vegetative propagation is difficult, a mass selection program should be undertaken. The worldwide progress achieved in breeding is obvious, in spite of the fact, that different strategies and methods are used country by country. The majority of plant materials under cultivation have been created by conventional selection methods, even today, including individual- mass, or special selection methods. More recently outstanding results are reported through hybridization and mutation.

\section{Successful Examples in Medicinal and Aromatic Plants}

Special high carvone content type plants have been produced by clonal selection from Mentha spicata (Shikimara et al., 1993). Citral rich populations from Ocimum americanum (Sarin et al., 1992) and Methyl cinnamate population from O. basilicum (Simon et al., 1990). In the case of genus Salvia, the selection proved to be a rather effective method. The first Salvia sclarea cultivars were developed using continuous individual selection (Bernath, 2000), and this method was applied in the case of Salvia officinalis with high efficacy.

Some examples of the intraspecific crossing of medicinal and aromatic plants for changing the accumulation of their active agents includes: Cymbopogon flexuosus, C. martinii, Melissa officinalis, Ocimum americanum, Salvia officinalis, Solanum laciniatum, Valeriana officinalis, Ocimum gratissimum and Thymus vulgaris.

With regard to mutation breeding, both the spontaneous and induced mutants are frequently used for improving genetic background of medicinal and aromatic plants. Among others, applying gamma-irradiation dwarf mutants of Jasminum grandiflorum (Srivastava and Karmakar, 1988) and Solanum laciniatum (Bernath and Tetenvi, 1973) were developed. The chemical mutagens were applied successfully too. The essential oil accumulation pattern of Cymbopogon flexuosus was modified by ethyl methanesulfonte (Kulkarni et al., 1992). More recently the alkaloid composition of poppy (Papaver somniferum) was modified by mutagenic treatments.

\section{Breeding in Medicinal and Aromatic Plants (Successful Examples in Commercially Important Species)}

\subsection{Mutation breeding in Plantago ovata (Isabgol)}

Plantago ovata, a medicinal herb, requires improvement in seed yield to meet world demand for its seed husk. Mutation breeding has been attempted on account of the narrow genetic base of the crop. Two mutagens, gamma rays and ethyl methane sulphonate were tried. The result obtained in all three replicates revealed that $20 \mathrm{kR}$ dose of gamma rays boosted seed yield by more than $200 \%$. The experiments were repeated during years between 1993-1995 and the results were confirmed. These results recorded a breakthrough in a crop not amenable to other techniques for improvement and are of great commercial value (Sareen and Koul, 1999).

Improved varieties of Plantago ovata in India are Gujarat Isabgol-1 and Gujarat Isabgol-2. Gujarat Isabgol-1 is developed through selection and gives $11 \%$ higher seed yield than the local check. Gujarat Isabgol-2 is developed through selection and gives $20 \%$ higher seed yield than GI-1.

5.2. Selection and breeding for high artemisinin yielding strains of Artemisia annua

Artemisinin (Qinghaosu), a sesquiterpene lactone endoperoxid isolated from the herb Artemisia annua, is a highly potent antimalarial compound. In view of finding high artemisinin yielding strains, $A$. annua of several origins were placed in cultivation in Switzerland in 1989 and 1990 and their content in artemisinin determined by HPLC using a reductive electrochemical detector. The average artemisinin concentration in plants of European origin range from 0.03 to $0.22 \%$ (dry leaves weight basis) artemisinin, but a clone from China could contain up to $1.1 \%$ artemisinin. As $A$. annua is a strongly outcrossing species, hybridizations have been made between the Chinese clone, propagated through in 
vitro techniques and pollen issued from plants from Italian, Yougoslavian and Spanish origins. These hybrids cultivated in Switzerland in 1990 and 1991 produced in average 0.64, $0.73 \%$ and $0.95 \%$ artemisinin, respectively for a yield of dry leaves of about $2000 \mathrm{~kg} \mathrm{ha}^{-1}$ (Delabays et al., 1993).

\subsection{Lemon basil (Ocimum basilicum) hybrid}

Lemon basil, Thai lemon basil or Lao basil (Ocimumx citriodorum) is a hybrid between basil (Ocimum basilicum) and African basil (Ocimum americanum). The herb is grown primarily in north eastern Africa and southern Asia for its strong fragrant lemon scent.

5.4. Development of improved clones of Jamrosa (Cymbopogon nardus)

Jamrosa, a hybrid clone of Cymbopogon, was considered to be a substitute for palmarosa oil ex. Cymbopogon martinii (Roxb.) Wats. var. martinii as the oil yield per hectare was almost double that of palmarosa. However, the presence of a significant percentage of the undesirable neral/geranial content in its oil masks the rosaceous odour of the oil. This has limited the scope of using Jamrosa oil directly as a source of geraniol. Moreover, over the years of cultivation of the crop, there has been deterioration in economically important characters of the crop.

In order to bring about necessary improvement in the crop, a genetic improvement program was initiated. Since the crop is totally sterile, conventional breeding techniques are of no consequence. The most potent method of improvement is thus use of ionizing radiation. With this in view, a program of induced mutation studies was initiated to induct, isolate and develop desired genotypes of the crop. Dormant vegetative slips of a single clone of Jamrosa of same age and size were subjected to various doses of gamma-ray treatment, doses ranging from 3-10 kR in three replications. Radiation source was gamma cell operating at dose rate of $2.0 \mathrm{R}$ minute ${ }^{-1}$. The irradiated clones along with the parental clones were planted in the experimental fields. Plants raised from irradiated plants were very carefully screened through visual and chemical analysis and were individually harvested.

Five mutant clones isolated exhibited variation in quality/ quantity of essential oil. These changes in oil characters were attributed to micro level mutations induced by gamma-rays. Subsequently, these five mutant clones were propagated and a large scale yield trial along with parental clone was conducted to ascertain the performance of each mutant clone. Examination of the data reveals that highest oil yield per hectare was obtained from variant RL-931 giving a 33\% increase in the oil yield over the parent clone (Kak et al., 2011).

\begin{tabular}{lcc}
\hline Oil yield & $(\mathrm{W} / \mathrm{W}) \%$ & Oil yield $\mathrm{ha}^{-1} \mathrm{~kg}$ \\
\hline Parent clone & 0.37 & 224.7 \\
RL-931 & 0.67 & 321.6 \\
\hline
\end{tabular}

5.5. Improved varieties of lemon grass (Cymbopogan flexuosus)

Variety CKP 25 which is a hybrid between $C$. khasianum $\times$ C. pendulus and gives $60 \mathrm{t} \mathrm{ha}^{-1}$ herbage in North Indian plains. The oil contains $82-85 \%$ citral. The major use of oil is as a source of citral, which goes in perfumery, cosmetics and beverages. The Citral rich oil has germicidal, medicinal and flavouring properties. (Farooqi and Sreeramu, 2001).

5.6. Hybrids obtained from crossing S. laciniatum and S. aviculare

Solanum laciniatum $(2 \mathrm{n}=92)$ contains up to $1 \%$ solasodine while, S. aviculare var. brisbanense $(2 n=46)$ contains up to $3 \%$ solasodine. Following polyploidization, the hybrids 727 and 728 were obtained from S. laciniatum $\times$ S. aviculare var. brisbanense and hybrid 730 from S. aviculare var. brisbanensexS. laciniatum. The $F_{1}$ hybrids $(2 n=92)$ were heterotic with abundant flowering and fruiting and had characters intermediate between the parental forms. In the $\mathrm{F}_{2}-\mathrm{F}_{4}$ the hybrids fell into four types:

(a) the S. laciniatum type;

(b) the S. aviculare type;

(c) an intermediate type; and

(d) new forms.

In the $\mathrm{F}_{3}$ and $\mathrm{F}_{4}$, a predominance of laciniatum characters was observed. In the $\mathrm{F}_{4}$, uniform valuable hybrids were obtained. In content of solasodine in the leaves the most promising hybrids exceeded the cultivated form by $20-30 \%$ (Vershinin and korneva, 1970).

\subsection{Improved varieties of Solanum laciniatum}

$\mathrm{NH} 88-12$ which is developed through selection and gives dry berry yield of $31.38 \mathrm{q} \mathrm{ha}^{-1}$ has solasodine content of $4.18 \%$ (in berries) and $1.74 \%$ (in leaves). This variety is suitable for sub temperate conditions.

\subsection{Improved varieties of Solanum viarum (Khasi kateri)}

Arka Mahima which is developed through Mutation and gives $2 \%$ solasodine content is a spineless variety. Arka Sanjeevani which is developed through selection has a spine free stem, high alkaloid content and is suitable for high density planting.

\subsection{Valeriana jatamansi (Mushakbala)}

Germplasm of Indian valerian having high valepotriates (4\%) has been developed and is registered by Plant germplasm registration committee (PGRC) of ICAR.

5.10. Hybrids of Opium poppy (Papaver somniferum) with changed morphine alkaloid content

The morphine content in eight varieties of opium poppy ranged between 11.84 to $14.78 \%$. The estimation of morphine strength was done on dry basis. However, one of the hybrids namely "Dhola Chhotta Gotia"× "Kantia Pink" had morphine strength (17.52\%) which was as high as $44.9 \%$ over its better parent. Overdominance for this character was present in 
gene action studies. In another combination with indigenous "Dhola Chhotta Gotia"×“EC 111569" (from Agricultural Research Centre, Beltsville, USA), the morphine strength was $19.56 \%$. Especially in advanced generations, where single plant samples in small quantities are available, the thin layer chromatographic method (TLC) of morphine estimation is advocated (Kaicker and Choudhury, 1983).

\subsection{Improved varieties of opium poppy in India}

1. Jawahar Opium 539 which is developed through selection and giving $65 \mathrm{~kg} \mathrm{ha}^{-1}$ latex yield and $14.85 \%$ morphine.

2. Jawahar Aphim 16 (JA-16) developed through selection and giving $60-65 \mathrm{~kg} \mathrm{ha}^{-1}$ latex yield and $12.5 \%$ morphine.

3. Jawahar Opium 540 is developed through selection and giving $75 \mathrm{~kg} \mathrm{ha}^{-1}$ latex yield and 13\% morphine.

4. Trishna which developed through selection and giving 49-53 $\mathrm{kg} \mathrm{ha}^{-1}$ latex yield and $14.78 \%$ morphine.

5.12. 'Varico 3', a new hybrid for thyme (Thymus vulgaris) production in Switzerland

Selection program was carried to optimize quality and yield of thyme (Thymus vulgaris) varieties, obtaining 56 new hybrids by crossing male sterile with male fertile clones. The most interesting one, named 'Varico 3', is characterized by high homogeneity, thymol chemotype, high essential oil content (5\%), same dry matter production as 'Varico2', the variety currently cultivated in Switzerland. Varico 3 was compared over three years (2007-2009) in plain and mountain to other thyme varieties from Switzerland, Germany and France. It's essential oil contains a powerful disinfectant called thymol that is effective against bacteria and fungi. Thymol also acts as an expectorant. Later herbalists listed thyme for these uses and as remedy for numerous other complaints, including diarrhoea and fever. They prescribed the oil externally as an antiseptic for fungal infections such as athlete's foot.

\subsection{A high yielding citral-rich strain of Ocimum americanum} L. from India

A new variety of Ocimum americanum $L$. rich in citral has been developed by natural selection and raised for two successive growing seasons to examine the seasonal variations in herb yield and oil content, chemical variation and citral content. The new strain was selected because it was a short duration crop for the production of citral-rich oil. Analysis of the oil revealed that the oil contained a total citral content of $76 \%$ (neral 23.0\%, geraniol 51.5\%) (Sarin et al., 1992).

5.14. Digoxin production in hybrids between Digitalis lanata and Digitalis grandiflora

Digitalis lanata is the only commercial source of the cardiac glycoside digoxin. It is an outbreeder and displays considerable variation. An attempt to increase uniformity was made by making $D$. lanataxD. grandiflora diploid hybrids and from these allotetraploid hybrids were produced using colchicine treatment. Such tetraploid plants would be homozygous. Tetraploid hybrids were shown to contain digoxin but at lower levels than in D. lanata. Progeny of selfed tetraploid hybrids were significantly more uniform than $D$. lanata grown from commercial seed but were considerably less vigorous. The results presented indicate that interspecific hybrids can be readily produced from $D$. lanata and $D$. grandiflora. Colchicine treatment provides fertile allotetra-ploids. The hope that these homozygous hybrids could be useful for commercial production was not, however, fulfilled. Although the hybrids contained digoxin, only a few had levels of the glycoside comparable with $D$. lanata. There was, however, considerable variation in the range of digoxin content from family to family. Since it may be expected that the digoxin content of the hybrid would be the result of the interaction of the $D$. lanata and $D$. grandiflora genomes, a primary selection among the parents may provide more promising results. The large reduction in vigour of the tetraploid hybrids compared with $D$. lanata may be a direct result of the homozygosity resulting from chromosome doubling

\subsection{Improved varieties of Withania somnifera (Ashwagandha)}

1. Jawahar Asgand-134 which is developed by selection from cross JA 20xWild type of Asgandha

2. Jawahar Asgand-20 which is developed by pureline selection 5.16. Improved varieties of Glycyrrhiza glabra (Liquorice)

Haryana Mulhatti-1 which is developed through selection from local race. Plant is erect and tall growing with broad and dark green leaves containing 6-7\% glycyrrhizin content

\subsection{Improved varieties of Cymbopogon martinii (Palmarosa)}

1. $\mathrm{Cl}-80-68$ which is developed through selection, gives $1-1.5 \%$ essential oil content.

2. Rosha Grass-49 which is developed through selection and yields $90 \%$ geraniol

\subsection{Improved varieties of Jasminum grandiflorum}

1. Arka Surabi which is developed through selection and flower yield is $10 \mathrm{t} \mathrm{ha}^{-1}$, is drought tolerant and yields essential oil $0.35 \%$.

2. Co 1 which is developed through clonal selection. Average flower yield is $10,144 \mathrm{~kg} \mathrm{ha}^{-1}$ in a year. It is suitable for oil extraction with a concrete recovery of $0.29 \%$.

\subsection{Genetic variability of the essential oil content of Melissa} officinalis

The essential oil content of various populations of Melissa officinalis (Lamiaceae) cultivated under Mediterranean climatic conditions (Ebro-Delta, Spain) has been investigated during five years of selection and improvement of the genetic plant material. Starting with an essential oil content of $0.2-0.3 \%$, a content of more than $0.5 \%$ was obtained as a result of genetic improvement. A weak negative correlation between the content of essential oil and phenotypical growth parameters such as the number of branches per plant and height was observed. No correlation between biomass production per plant and essential oil content could be found. By the method of hybridization, $M$. officinalis synthetics with a 
high yield of biomass and essential oil content were selected.

\section{Varietal Development}

Multi-location evaluation trials conducted under the AICRP on Medicinal and Aromatic Plants have resulted in the identification and release of twenty five new improved varieties of medicinal plants of fourteen species and seven varieties of aromatic plants of six species.

\begin{tabular}{|c|c|c|c|c|}
\hline Sr. No. & Crop & Variety & Developed at & Year of release \\
\hline \multicolumn{5}{|c|}{ Medicinal plants } \\
\hline 1. & Chlorophytum borivilianum (Safed musli) & JS405 & Mandsaur & 2004 \\
\hline 2. & Cassia angustifolia (Senna) & Anand Late Selection & Anand & 1989 \\
\hline 3. & Diascoria floribunda & $\mathrm{FB}(\mathrm{C})-1$ & Bangalore & 1974 \\
\hline 4. & Diascoria floribunda & Arka Upakar & Bangalore & 1980 \\
\hline 5. & Digitalis lanata (Foxglove) & D.76 & Solan & 1991 \\
\hline 6. & Glaucium flavum (Yellow Horned Poppy) & $\mathrm{H} 47-3$ & Solan & 1991 \\
\hline 7. & Glycyrrhiza glabra (Liquorice) & Haryana Mulhatti-1 & Hisar & 1989 \\
\hline 8. & Hyoscyamus muticus (Egyptian Henbane) & HMI-80-1 & Indore & - \\
\hline 9. & Lepidium sativum (Cress) & GA-1 & Anand & 1998 \\
\hline 10. & Rauvolfia serpentina (Sarpagandha) & $\mathrm{RI}-1$ & Indore & - \\
\hline 11. & Papaver somniferum (Opium poppy) & Jawahar Aphim 16 & Mandsaur & 1984 \\
\hline 11. & Papaver somniferum (Opium poppy) & Kirtiman & Faizabad & 1990 \\
\hline 13. & Papaver somniferum (Opium poppy) & Jawahar Opium 539 & Mandsaur & 1997 \\
\hline 14. & Papaver somniferum (Opium poppy) & Jawahar Opium 540 & Mandsaur & 1998 \\
\hline 15. & Papaver somniferum (Opium poppy) & Chetak Aphim & Udaipur & 1994 \\
\hline 16. & Papaver somniferum (Opium poppy) & Trisna & Delhi & - \\
\hline 17. & Piper longum (Long pepper) & Viswam & Trichur & 1996 \\
\hline 18. & Plantago ovata (Isabgol) & Gujarat Isabgol- 1 & Anand & 1976 \\
\hline 19. & Plantago ovata (Isabgol) & Gujarat Isabgol-2 & Anand & 1983 \\
\hline 20. & Plantago ovata (Isabgol) & Haryana Isabgol-5 & Hisar & 1989 \\
\hline 21. & Plantago ovata (Isabgol) & Jawahar Isabgol-4 & Mandsaur & 1996 \\
\hline 22. & Solanum laciniatum & NH 88-12 & Solan & 1991 \\
\hline 23. & Solanum viarum (Khasi Kateri) & Arka Sanjeevani & Bangalore & 1989 \\
\hline 24. & Solanum viarum (Khasi Kateri) & Arka Mahima & Bangalore & 1992 \\
\hline 25. & Withania somnifera (Aswagandha) & Jawahar Asgand-20 & Mandsaur & 1989 \\
\hline 26. & Withania somnifera (Aswagandha) & Jawahar Asgand-134 & Mandsaur & 1998 \\
\hline \multicolumn{5}{|c|}{ Aromatic plants } \\
\hline 1. & Cymbopogon flexuosus (Lemon Grass) & NLG-84 & Faizabad & 1994 \\
\hline 2. & C. martinii var. motia (Palmarosa) & Rosha Grass-49 & Hisar & 1989 \\
\hline 3. & C. martinii var. motia (Palmarosa) & $\mathrm{Cl}-80-68$ & Indore & _ \\
\hline 4. & Jasminum grandiflorum (Jasmine) & Arka Surabhi & Bangalore & 1993 \\
\hline 5. & Mentha spicata (Spearmint) & Punjab Spearmint-1 & Solan & 1991 \\
\hline 6. & Valeriana jatamansi (Mushakbala) & Dalhousi Clone & Solan & 1994 \\
\hline 7. & Vetiveria zizanioides (Vetiver) & Hyb-8 & Delhi & _- \\
\hline
\end{tabular}

\section{Conclusion}

Breeding has become one of the most important factors for advancement of the medicinal and aromatic plants branch because the genotypes can be adapted to the demands of the 
stakeholders in the production chain. Thus, plants with useful characters, resistance to biotic and abiotic stress, increased yield and early maturity can be developed through different conventional genetic improvement methods especially selection. Improved strains should be developed in case of high altitude medicinal plants with early maturity, higher active content and biomass.

\section{References}

Bernath, J., 2000. Genetic improvement of cultivated species of the genus Salvia. In: Kintzios, E., Sage - The genus Salvia. Harwood Academic Publisher 4, 109-124.

Bernath, J., Tetenyi, P., 1973. Terallas hatasa a .determinalt. és a normal habitusu (Solanum laciniatum Ait.) novenyekre. Herba. Hung 12, 17-25.

Delabays, N.G., Collet, S., Benakis, A., 1993. Selection and breeding for high artemisinin (qinghaosu) yielding strains of Artemisia annua. Acta Horticulturae 330: WOCMAP I - Medicinal and Aromatic Plants Conference: part 4 of 4.

Farooqi, A., Sreeramu, B.S., 2001. Cultivation of Medicinal and Aromatic crops. Universities Press (India) Itd. Hyderabad, 506.

Kaicker, U.S., Choudhury, B., 1983. Hybrids of opium poppy (Papaver somniferum) with changed morphine alkaloid content. Acta Horticulturae 132: III International symposium on spice and medicinal plants, xxi IHC.

Kak, S.N., Bhan, M.K., Rekha, K., 2011. Development of Improved Clones of Jamrosa (Cymbopogon nardus (L.)
Rendlevar. Confertiflorus (Steud.) Bor. x C. jwarancusa (Jones) Schult.) through induced mutations. Journal of Essential Oil Research 12, 108-110.

Kulkarni, R.N., Mallavarapu, G.R., Ramesh, S., 1992. The oil content and composition of new variants of Cymbopogon flexuosus. Journal of Essential Oil Research 4, 511-514.

Sareen, S., Koul, A.K., 1992. Mutation breeding in improvement of Plantago ovata Forsk. The Indian Journal of Genetics and Plant Breeding 59, 337-344.

Sarin, Y.K., Agarwal, S.G., Thappa, R.K., Kuldeep, S., Kapahi, B.K., Singh, K., 1992. A high yielding citral-rich strain of Ocimum americanum L. from India. Journal of Essential Oil Research 4, 515-519.

Shikimara, A.F., Vorebeva, E.A., Kubrak, M.N., Buga, T.V., 1993. Terpenoid composition of the essential oil in the carvone chemotype of spearmint. Bulletin of the Moldavian Academy of Sciences 5, 75-76.

Simon, J.E., Quinn, J., Murray, R.G., 1990. Basil: a source of essential oils. Proceedings of First International Symposium on New Crops (23-26 October, 1988), 484-489.

Srivastava, H.C., Karmakar, P.G., 1988. Spontaneous dwarf mutant in Jasminium grandiflorum L. Herba. Hung 27, 57-59.

Vershinin, V.A., Korneva, E.I., 1970. A study of hybrids obtained from crossing S. laciniatum Ait. and S. aviculare Forst. Sb. nauch. rabot. VNII lekarstv. rast. 2, 73-79. 